\section{Isquemia de extremidades inferiores secundaria a arteritis de la arteria temporal}

\author{
CRISTIAN ZÁRATE B. ${ }^{1}$, MARÍA EUGENIA MARTÍNEZ R-E. ${ }^{2}$, \\ PEDRO SFEIR V. ${ }^{1}$, OBREN DRAZIC B. ${ }^{1}$, JOSÉ F VARGAS S. ${ }^{1}$, \\ JOSÉ I. TORREALBA F. ${ }^{1}$, MICHEL BERGOEING R. ${ }^{1}$, \\ LEOPOLDO MARINÉ M. ${ }^{1}$, FRANCISCO VALDÉS E., \\ RENATO MERTENS M. ${ }^{1}$
}

\section{Lower limb ischemia in giant cell arteritis. Report of one case}

Giant cell arteritis is more common in women older than 60 years, is associated with systemic inflammation symptoms and mainly involves the aortic arch and cranial arteries, specially the temporal artery. Symptomatic lower extremity arterial stenosis or occlusion is uncommon and can lead to limb loss. We report a 73-year-old woman presenting with a one-month history of lower extremity intermittent claudication of sudden onset. She also complained of fever, malaise, headache and weight loss. A non-invasive vascular study showed moderate femoral popliteal occlusive disease, with and abnormal ankle-brachial index ( 0.68 and 0.83 on right and left sides, respectively). An angio-computed tomography showed thickening of the aortic wall and severe stenosis in both superficial femoral arteries. Steroidal treatment was started, and a temporal artery biopsy was performed confirming giant cell arteritis. Six weeks after steroid therapy the patient had a complete remission of symptoms. A serologic exacerbation was subsequently treated with a humanized monoclonal antibody against the interleukin-6 receptor Tocilizumab, obtaining long time remission.

(Rev Med Chile 2020; 148: 1513-1517)

Key words: Arteritis; Giant Cells; Giant Cell Arteritis; Femoral Artery.

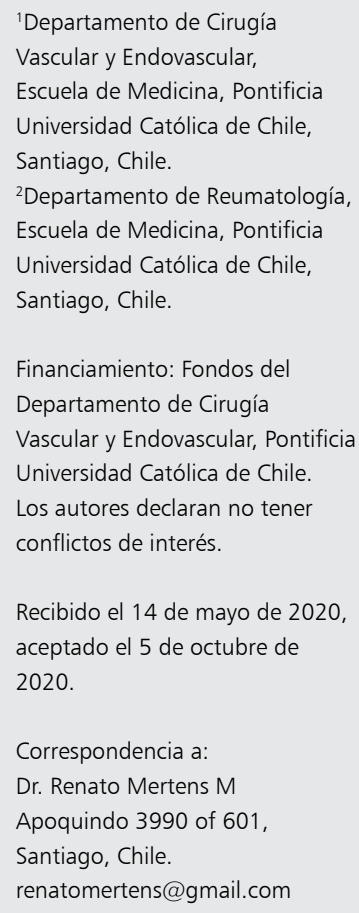

L a arteritis de la arteria temporal (AAT) pertenece a la familia de las arteritis de células gigantes (ACG) y es la vasculitis sistémica más frecuente en adultos, afectando principalmente a la población femenina mayor de 50 años con un peak de incidencia a los 80 años $^{1}$. Afecta inicialmente las ramas extracraneales de la arteria carótida, siendo menos frecuente el compromiso de otros vasos. El compromiso vascular de extremidades es muy infrecuente, sin embargo, existen reportes aislados de pacientes con isquemia crítica de extremidades inferiores asociados a $\mathrm{AAT}^{2,3}$. Se describe a continuación la historia clínica y el manejo de un caso de isquemia de extremidades inferiores secundaria a AAT.

\section{Caso clínico}

Paciente de sexo femenino de 73 años con antecedentes de artrosis de manos, hipotiroidismo y meningioma. Refiere cuadro clínico de claudicación intermitente clásica de extremidades inferiores a 300 metros, de aparición súbita un mes antes de consultar. Refiere además aparición concomitante de compromiso del estado general, cefalea, calofríos vespertinos, sensación febril, su- 
doración nocturna y baja de peso de aproximadamente 5 kilos. Al examen físico destacaban pulsos femorales conservados y poplíteos hacia distal ausentes. Se complementó evaluación con estudio vascular no invasivo, evidenciando enfermedad arterial fémoro poplítea y distal moderada, de predominio derecho con índice tobillo brazo (ITB) 0,68 a derecha y 0,83 a izquierda (Figura 1A). En los exámenes de laboratorio destacaba anemia con hemoglobina $10,3 \mathrm{~g} / \mathrm{dl}$, leucocitos 8.700 , velocidad de sedimentación de $103 \mathrm{~mm}$ a la hora y proteína $\mathrm{C}$ reactiva de $18,9 \mathrm{mg} / \mathrm{dl}$ (valor normal hasta 0,5 $\mathrm{mg} / \mathrm{dl}$ ). Inmunofijación de inmunoglobulinas en sangre y orina, y razón Kappa/Lambda fueron normales. Por sospecha de enfermedad embólica secundaria a endocarditis infecciosa se inicia anticoagulación con enoxaparina y se realizó ecocardiografía transesofágica sin hallazgos sugerentes de vegetaciones. Se realizó tomografía axial computada en fase angiográfica que descartó la precencia de embolías, trombosis o lesiones ateromatosas y evidenció engrosamiento parietal difuso de aorta tóraco-abdominal, vasos supra aórticos, origen de tronco celiaco y estenosis larga, cilíndrica y concéntrica, de contorno luminal suave de ambas arterias femorales superficiales, sin calcificación, con el aspecto característico de vasculitis (Figura 2). Ante la evidencia de una arteritis clínica y morfológica de distribución característica muy sugerente de arteritis de células gigantes, se decidió proceder con biopsia de arteria temporal y no con ecografía o PET CT, debido a la relevancia de tener diagnóstico histolólogico y confirmar la artritis que clínica y morfológicamente era altamente probable. Posteriormente se inició de inmediato prednisona (PDN) $40 \mathrm{mg}$ día y $20 \mathrm{mg}$ noche asociado a aspirina $81 \mathrm{mg}$ día y rivaroxaban $15 \mathrm{mg}$ día para prevención de trombosis en relación a las estenosis descritas, siendo dada de alta al primer día post operatorio de su biopsia.

La biopsia evidenció hiperplasia de la íntima e infiltrado inflamatorio de linfocitos y plasmocitos en la adventicia y parte de la túnica muscular, y focos con microgranulomas y células gigantes multinucleadas compatible con el diagnóstico clínico de arteritis de células gigantes (Figura 3).

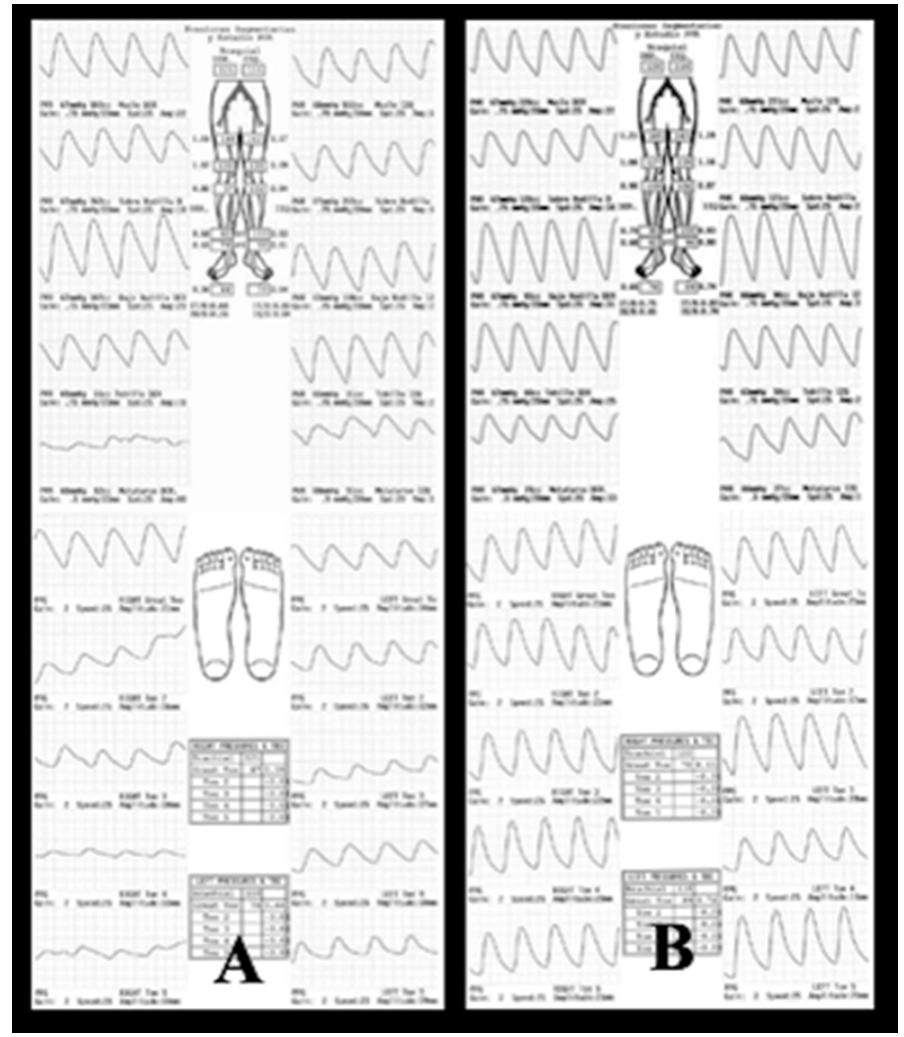

Figura 1. Estudio vascular no invasivo al ingreso (A) y a las 6 semanas de tratamiento (B). 

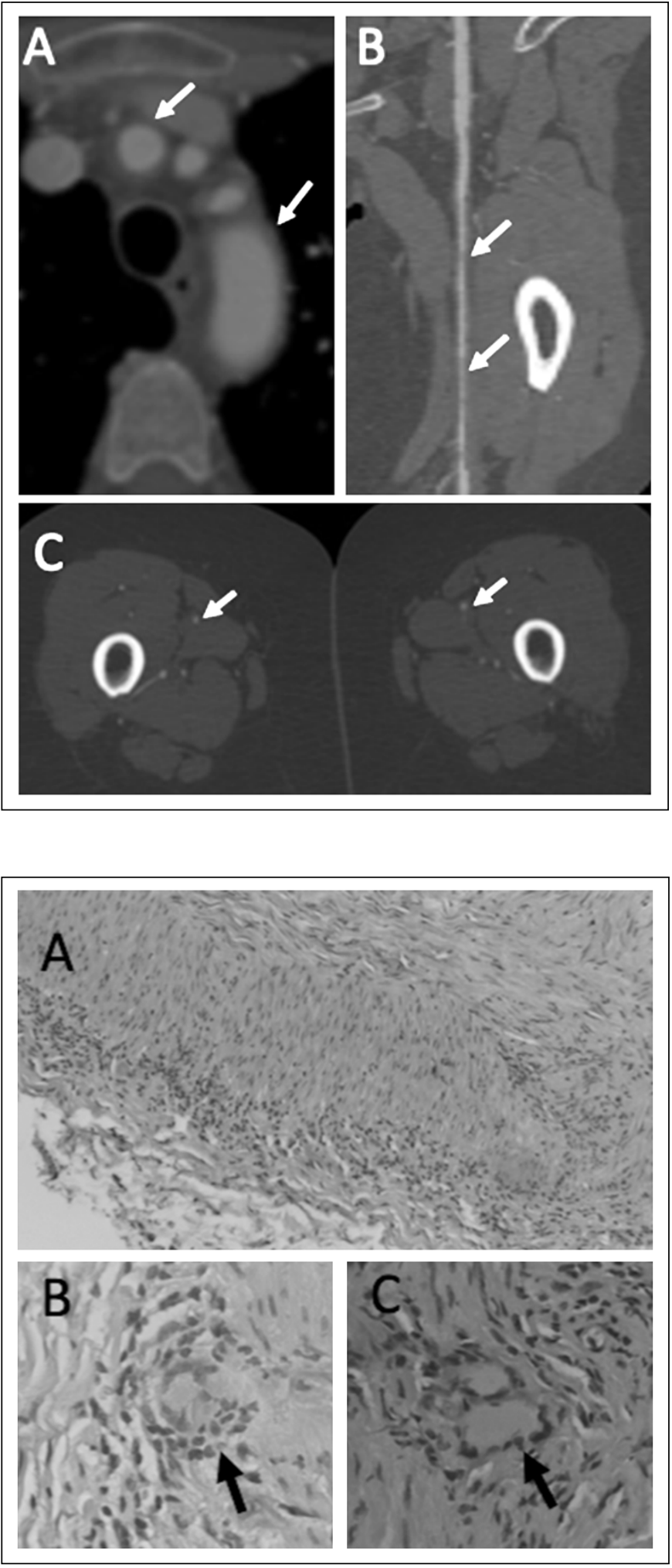

Figura 3. Histologia biopsia arteria temporal (tinción hematoxilina-eosina), las flechas en B y C señalan celulas gigantes características. 
Es derivada a Reumatología para el tratamiento de su vasculitis. Se mantiene con PDN en dosis de $1 \mathrm{mg} / \mathrm{kg}$ por 1 mes y aspirina $81 \mathrm{mg} /$ día observándose junto a la mejoría clínica descrita , normalización del hemograma, VHS y PCR a las tres semanas post alta. Evaluada de forma ambulatoria por cirugía vascular en forma seriada, encontrándose completamente asintomática y sin claudicación intermitente a las 6 semanas posterior al alta. Al examen físico destacaba reaparición de pulsos popliteos y distales bilateral. El estudio vascular no invasivo de extremidades inferiores reveló normalización de ITB bilateral como también las curvas de pletismografía (Figura 1B). Se inició luego descenso gradual de prednisona, y cuatro meses posteriores al inicio del tratamiento cuando estaba con $15 \mathrm{mg} /$ día de PDN, la paciente sufre una recaída con reaparición de la anemia y elevación de VHS y PCR, sin claudicación de extremidades inferiores. Se agrega entonces Tocilizumab, anticuerpo monoclonal anti receptor de IL6, 162 mg subcutáneo, cada 15 días, de acuerdo a datos recientes y aprobación de la FDA para su uso en arteritis de celúlas gigantes, lográndose una remisión mantenida y disminución de la PDN a $5 \mathrm{mg} /$ día $^{4-6}$.

Trabajo cuenta con aceptación de la paciente para su publicación

\section{Discusión}

En 1932 Horton y cols ${ }^{7}$ describieron por primera vez los hallazgos histopatológicos de arteritis de células gigantes. Posteriormente Jennings y $\mathrm{Camb}^{8}$ describieron el compromiso extracraneal de la enfermedad. Klein et al, en 248 pacientes con AAT, evidenciaron solo 34 pacientes con compromiso de aorta y/o de sus ramas ${ }^{9}$. El compromiso de vasos extracraneales está presente en 10 a $15 \%$ de los casos, siendo la arteria subclavia y axilar las más frecuentemente afectadas. Los primeros registros de compromiso vascular de extremidades por AAT se obtuvieron por resultados de autopsias de pacientes asintomáticos, por lo cual, su prevalencia se considera subestimada. En una serie de 6212 pacientes con AAT, solo $0,3 \%$ presentó isquemia de extremidades inferiores, siendo la arteria femoral superficial la más frecuentemente afectada, seguida de la arteria poplítea $^{3}$. Actualmente con el uso de PET -CT se ha estimado una prevalencia de compromiso de arteria femoral de $37 \%$ en pacientes con $\mathrm{AAT}^{10}$. El compromiso arterial se origina por dos mecanismos: inflamación de pared arterial durante la fase aguda y eventualmente ateroesclerosis secundaria a inflamación crónica ${ }^{11}$.

Le Hello y cols ${ }^{2}$, describieron a 8 pacientes con AAT y compromiso de extremidades inferiores y analizando además los 18 casos publicados hasta ese momento, destacando la claudicación progresiva de inicio brusco y bilateral como síntoma eje, sin la necesidad de presentar los clásicos síntomas de AAT como cefalea, claudicación mandibular o fiebre entre otros. De ellos, siete pacientes presentaban isquemia crítica al momento del diagnóstico. Al igual que lo descrito en la literatura, en nuestro caso el síntoma eje fue la claudicación bilateral de aparición brusca, sin lesiones tisulares por isquemia, pero asociado a un marcado cuadro inflamatorio sistémico. En esta paciente destaca además, la falta de sintomas craneales caracteristicos de AAT; éstos se han reportado negativos hasta en $50 \%$ de los pacientes con compromiso arterial de las extremidades inferiores ${ }^{3}$.

Las características angiográficas pueden ser inespecíficas y ser confundidas con lesiones ateroescleróticas con estenosis aisladas y/o en tándem y áreas de trombosis, pero también puede mostrar lesiones estenóticas largas y de lumen regular, como en este caso, que sugieren una vasculitis ${ }^{2}$. Por esta razón el estudio con tomografía computada es útil ya que permite visualizar el grosor de la pared arterial y los hallazgos que confirman la sospecha de vasculitis.

El inicio precoz de terapia con corticoides es fundamental para evitar progresión de la enfermedad que puede llegar a comprometer la viabilidad de la extremidad, con una respuesta clínica rápida en etapas agudas ${ }^{12}$. En esta paciente dado la recaída de su enfermedad sitémica al bajar la dosis de esteroides, el tratamiento con Tocilizumab permitió la remisión mantenida de la vasculitis y fue útil para bajar la dosis de esteroides, evitando sus complicaciones. Stone et $\mathrm{al}^{4}$ reporta en 251 pacientes con arteritis de la temporal tratados con Tocilizumab subcutáneo, en esquema semanal o quincenal, una tasa de respuesta medida como remisión mantenida sin corticoides a las 52 semanas de $56 \%$ o $53 \%$ respectivamente, comparado con una tasa de $14 \%$ a $18 \%$ en los grupos que recibieron sólo corticoides. Este efec- 
to del Tocilizumab se observó en arteritis recién diagnosticada asi como también cuando se inició posterior a recaidas. Otros inmunosupresores no han demostrado utilidad ${ }^{13}$. En nuestro caso, ante los hallazgos clínicos e imagenológicos se inició de forma precoz terapia con corticoides previo a resultado histopatológico de la biopsia, asociado a antiagregación plaquetaria y anticoagulación para disminuir el riesgo de trombosis en áreas estenóticas, logrando remisión completa de síntomas a las 6 semanas. El tratamiento con Tocilizumab permitió la remisión posterior a la recaida sin necesidad de aumentar las dosis de corticoides evitando así los efectos secundarios importantes del uso prolongado de corticoides especialmente en pacientes mayores.

El tratamiento quirúrgico con puentes arteriales ha presentado alta tasa de oclusión precoz $^{12}$. Se ha descrito angioplastia con balón como terapia adyuvante al pulso de corticoides logrando tasas de permeabilidad primaria y secundaria de 65,2 y $89,7 \%$ respectivamente ${ }^{14}$. Dados los excelentes resultados del tratamiento médico, creemos que la revascularización debe reservarse solo para casos de isquemia crítica con riesgo de pérdida de la extremidad.

En resumen, la isquemia de extremidades inferiores secundario a AAT es una entidad clínicamente poco frecuente que requiere de una alta sospecha en pacientes con claudicación intermitente aguda asociada a un cuadro inflamatorio sistémico, por esto último se debe descartar una embolía secundaria a endocarditis. Puede llevar a pérdida de extremidad, pero el tratamiento precoz con corticoides logra revertir las estenosis y sus síntomas con una tasa de éxito cercana a 100\%.

\section{Referencias}

1. Warrington KJ, Leslie T. Cooper J. Vasculitis and Other Uncommon Arteriopathies. In: Rutherford's Vascular Surgery, 8th Edition; 2014: 1154-66.
2. Le Hello C, Lévesque H, Jeanton M. Lower limb giant cell arteritis and temporal arteritis: followup of 8 cases. J Rheumatol 2001; 28 (6): 1407-12.

3. Kermani TA, Matteson EL, Hunder GG, Warrington KJ. Symptomatic lower extremity vasculitis in giant cell arteritis: A case series. J Rheumatol 2009; 36 (10): 2277 83.

4. Stone JH, Tuckwell K, Dimonaco S, et al. Trial of tocilizumab in giant-cell arteritis. N Engl J Med 2017; 377 (4): 317-28.

5. Serling-Boyd N, Stone JH. Recent advances in the diagnosis and management of giant cell arteritis. Curr Opin Rheumatol 2020; 32 (3): 201-7.

6. Hellmich B, Agueda A, Monti S. 2018 Update of the EULAR recommendations for the management of large vessel vasculitis. Ann Rheum Dis. 2020;79(1):19-130.

7. Bayard Horton. Arteritis of the Temporal Arteries. Arch Intern Med 1934; 53 (3): 400-9.

8. G.H Jennings, M.B Camb. Arteritis of the temporal vessels. Lancet 1938; 231: 424.

9. Klein RG, Hunder GG, Stanson AW, Sheps SG. Large artery involvement in giant cell (temporal) arteritis. Ann Intern Med 1975; 83 (6): 806-812.

10. Blockmans D, Ceuninck L de, Vanderschueren S, Knockaert D, Mortelmans L, Bobbaers H. Repetitive18F-fluorodeoxyglucose positron emission tomography in giant cell arteritis: A prospective study of 35 patients. Arthritis Rheum 2006; 55 (1): 131-7.

11. Ungprasert $\mathrm{P}$, Thongprayoon $\mathrm{C}$, Kittanamongkolchai W, Srivali N, Cheungpasitporn W. Peripheral arterial disease in patients with giant cell arteritis: a meta-analysis. Int J Rheum Dis 2016; 19 (8): 819-25.

12. Loo ZY, Thwaites S, Kyaw P. Giant cell arteritis presenting as critical lower limb ischemia. Vasc Endovascular Surg 2013; 47 (8): 660-2.

13. Hoffman GS, Cid MC, Hellmann DB, et al. A multicenter, randomized, double-blind, placebo-controlled trial of adjuvant methotrexate treatment for giant cell arteritis. Arthritis Rheum 2002; 46 (5): 1309-18.

14. Both M, Aries PM, Müller-Hülsbeck S, et al. Balloon angioplasty of arteries of the upper extremities in patients with extracranial giant-cell arteritis. Ann Rheum Dis 2006; 65 (9): 1124-30. 